\title{
Linking stakeholder engagement to profitability through sustainability- oriented innovation: a quantitative study of the minerals industry
}

\author{
Marcel Bogers ${ }^{1,2, *}$, Babak Ghassim ${ }^{3}$ \\ ${ }^{1}$ Unit for Innovation, Entrepreneurship and Management, Department of Food and Resource Economics, University of \\ Copenhagen, Rolighedsvej 25, 1958 Frederiksberg C, Denmark; marcel@ifro.ku.dk \\ ${ }^{2}$ Garwood Center for Corporate Innovation, F402 Haas School of Business, \#1930, University of California, Berkeley, \\ Berkeley, CA 94720-1930, USA \\ ${ }^{3}$ The School of Business and Economics, UiT-The Arctic University of Norway, Breivangvegen 23, 9010 Troms $\phi$, Norway; \\ babak.ghassim@uit.no
}

* Corresponding author 


\title{
Linking stakeholder engagement to profitability through sustainability- oriented innovation: a quantitative study of the minerals industry
}

\author{
Marcel Bogers ${ }^{1,2, *}$, Babak Ghassim ${ }^{3}$ \\ ${ }^{1}$ Unit for Innovation, Entrepreneurship and Management, Department of Food and Resource Economics, University of \\ Copenhagen, Rolighedsvej 25, 1958 Frederiksberg, Denmark; marcel@ifro.ku.dk \\ ${ }^{2}$ Garwood Center for Corporate Innovation, F402 Haas School of Business, \#1930, University of California, Berkeley, \\ Berkeley, CA 94720-1930, USA \\ ${ }^{3}$ The School of Business and Economics, UiT-The Arctic University of Norway, Breivangvegen 23, 9010 Troms $\phi$, Norway; \\ babak.ghassim@uit.no
}

\begin{abstract}
Firms' capability to develop sustainability-oriented innovation (SOI) can be enhanced by stakeholder engagement (SE) in order to acquire a wide range of external knowledge to support innovation efforts and outcomes. While we understand some of the transactional and relational attributes at stake for firms to leverage engagement with external stakeholders, we do not yet fully understand all the underlying mechanisms that are conducive to greater SOI outputs. At the same time, stakeholder theory emphasizes the importance of such engagement for firms' financial performance (FP), even though the related findings are far from conclusive. Therefore, this paper suggests and tests a mediation model to investigate the associations between SE, SOI and FP. Based on data collected from 101 mineral companies in Norway, the results show that both transactional and relational interactions are important for improving SOI outputs, and that SOI fully mediates the association between SE and FP (measured by profitability). This suggests that external engagement activities do not directly link to FP, and that the financial benefit begins to appear once a firm is able to transform the acquired knowledge from external stakeholders into innovative outputs. Such open innovation approach thus requires a sustainability orientation to ultimately materialize into a performance benefit.
\end{abstract}

Keywords: stakeholder engagement; open innovation; sustainability; profitability; mediator

Acknowledgement: Marcel Bogers would like to acknowledge the support of the Novo Nordisk Foundation (grant number: NNF16OC0021630).

\section{Introduction}

The increase in both size and significance of social and environmental challenges has made it inevitable for firms to integrate these aspects of sustainability with their main strategic focus on profit seeking (Hall \& Vredenburg, 2003). This has led to the emergence of a corporate sustainability perspective, which proposes economic, environmental and social sustainability as pathways to gain competitive advantage (Amini \& Bienstock, 2014; Hart, 1995). In this case, practicing socio-environmental sustainability follows a 'business case for sustainability' logic (Schaltegger et al., 2012), in which managers seek economic success at the same time as performing better in social and environmental aspects. They do this, for instance, by improving their corporate image and gaining social legitimacy.

The role of innovation in the quest for sustainability has received considerable attention from academics and businesses. It has been argued that firms have no choice but to make sustainability-oriented 'changes' to the status quo of the value chain, product/service offerings

* Corresponding author 
and business model in order to remain competitive (Nidumolu et al., 2009). More specifically,

Previous research suggests that engaging stakeholders is a prerequisite for overcoming the complexity and uncertainty of SOI, as it enables firms to incorporate external knowledge into their innovation processes (Rodriguez et al., 2002; Segarra-Oña et al., 2017). Such studies further evidence the necessity of going beyond engaging primary stakeholders (those within the supply chain) and considering secondary stakeholders (e.g. environmental activists, universities and local communities) to be even more important in the context of SOI (Hall \& Martin, 2005). What we already know from the emerging literature on SE and SOI is centered either on the characteristics and various roles of stakeholders (Goodman et al., 2017), or on the organizational capabilities required for effective learning to take place (Kazadi et al., 2016). However, the conceptual argument that engaging more stakeholder groups is beneficial for firms' capability to achieve innovative outputs has not yet been fully explored and has yet to be examined empirically. At the same time, there is an emerging literature on open innovation that emphasized the importance of relying on external sources of knowledge to accelerate innovation (Bogers et al., 2017, 2018; Laursen \& Salter, 2006; West \& Bogers, 2014).

Moreover, engaging external stakeholders (more often secondary ones) is sometimes incorrectly perceived as costly and beyond the core business activity (Nidumolu et al., 2009; Sharma, 2005). Therefore, lack of knowledge about the significance of SE might impede managers' ability to fully recognize the value of such engagements in terms of financial returns. While examining the performance outcomes of SE has been a major theme in the previous research, mixed findings make it difficult to understand the exact association between firms' SE practices and their performance (Laplume et al., 2008). Rather than being a straightforward association, organizational resources and capabilities might mediate the effect of firms' activities related to stakeholders and socio-environmental management on their performance (Dixon-Fowler et al., 2013; Martinez-Conesa et al., 2017). Considering that innovation capability is among the most important determinants of firm performance (Mone et al., 1998), it could be considered as a mediating factor that enables firms to transform external stakeholders' knowledge into financial benefits.

Therefore, this study addresses three research questions: (1) To what extent does SE affect a firm's SOI outputs; (2) Does increasing engagement and SOI outputs relate to higher profitability?; and (3) Is SOI a mediator in the association between SE and FP? To address the first question, we follow Jones (1995) in distinguishing between transactional and relational interactions with external stakeholders, hence defining 'high SE' to be high in terms of both quality and quantity (Greenwood, 2007). In light of such framing, we not only examine the empirical association between SE and firm-level outcomes that has not been sufficiently examined previously (Watson et al., 2017), but also provide a theory-informed explanation of why it is expected (or perhaps not expected) that engaging external stakeholders (through different modes of interaction) improve SOI outputs.

Subsequently, by building on the natural resource-based view (NRBV) of the firm, we argue that SOI outputs in terms of processes, products and organizational practices act as a capability through which firms can continuously respond to sustainability challenges, thereby 
improving their competitiveness (Hart \& Dowell, 2011), in this case measured as profitability.

\section{Literature review and hypotheses}

\subsection{Theoretical background}

Sustainable development, as an overarching concept, proposes a mindset for growth that "meets the needs of the present without compromising the ability of future generations to meet their own needs" (WECD, 1987, p. 8). Subsequently, Elkington (1999) has extended this concept to the business level through his 'Triple Bottom Line (TBL)' approach, arguing that businesses should satisfy three criteria in order to ensure long-term success: economic prosperity, environmental protection and social equity. By building on the TBL approach, Wilson (2003) further elaborates that 'corporate sustainability' is a management paradigm that recognizes the significance of environmental and social performance, in addition to profitability. It is important to note that the economic, environmental and social aspects of corporate sustainability are interrelated (Amini \& Bienstock, 2014), in the sense that despite their inherent contradictions, they should be pursued simultaneously by adopting combinations of different strategies at the firm level (Hahn et al., 2015).

Similar to the competitive landscape, firms' innovation practices have also undergone changes, driven by the broad corporate sustainability perspective (Nidumolu et al., 2009). It has been argued that innovation for corporate sustainability, referred to as sustainabilityoriented innovation (SOI), lays the foundation for the transition towards more profitable, socially acceptable and cleaner business practices (Klewitz \& Hansen, 2014). Adams et al. (2016, p. 181) define SOI as "making intentional changes to an organization's philosophy and values, as well as to its products, processes or practices to serve the specific purpose of creating and realizing social and environmental value in addition to economic returns". While several concepts (such as green innovation, CSR-innovation and eco-innovation) exist at the intersection of innovation with different aspects of sustainability, SOI seems to be more aligned with the holistic approach to sustainability. Accordingly, this paper adopts a broadened view of SOI, as it better reflects the diverse range of challenges in industrial settings, particularly in the case of mineral companies which need to balance the economic, environmental and social aspects of their business (Laurence, 2011).

While adopting an innovative approach to improving individual aspects of sustainability is neither new in research nor in practice, what differentiates SOI from the traditional approaches to innovation is the multiplicity of purposes, impacts and focus areas, which 
adds to the complexity and uncertainty associated with innovation activities (Jay \& Gerard, contexts (Clarke \& Roome, 1999), where incorporating environmental and social considerations requires knowledge about technologies, regulative standards and societal expectations.

Uncertainty, on the other hand, points to the risks and costs associated with SOI. Social and environmental improvements might be achieved at the expense of increasing the cost of processes and products, which could result in the market and system failures of innovations (Foxon \& Pearson, 2008). SOI, with its potential impact on wider groups of stakeholders, may create conflict situations due to the opposing interests between the focal firm and its stakeholders, for instance local communities (Hall \& Martin, 2005; Watson et al., 2017). Because of these uncertainties, the desired outcome from SOI (e.g. the market success of green products) is likely to be unknown. Below, we discuss the ways in which SE may enable firms to overcome the complexity and uncertainty of SOI.

\subsection{Leveraging stakeholders' knowledge for SOI}

Before proceeding, it is necessary to have a clear understanding of the terms 'stakeholder' and 'stakeholder engagement'. A stakeholder "is any group or individual who can affect, or is affected by, the achievement of a corporation's purpose" (Freeman, 2010, p. 9). With regard to SE, although no single definition exists, we follow Greenwood (2007, pp. 317-318), who defines it as "practices that the organization undertakes to involve stakeholders in a positive manner in organizational activities." He separates SE from corporate responsibility, which is a purely moral attitude, and considers engagement practices as strategic efforts through which "an organization responds to the needs of stakeholders with the aim of furthering the goals of the organization" (Greenwood, 2007, p. 324). This implies the creation of mutual value for firms and their wider groups of stakeholders, as one of the tenets of corporate sustainability (Hörisch et al., 2014). By means of addressing socio-environmental sustainability through their interactions with stakeholders, firms strive to maximize the value accrued to their shareholders and other economic stakeholders.

In Hall et al.'s opinion (2003), SOI complexity and uncertainty at the firm level are essentially the result of the lack of internal knowledge about the technological and social aspects of sustainability, which in turn impedes effective decisions. In this regard, engaging stakeholders in innovation processes provides access to their needs and expectations (Luyet et al., 2012), improves firms' internal capacity to understand their stakeholders' language (Veldhuizen et al., 2013), and nurtures trust-based dialogue between firms and their societal stakeholders, which all imply increased knowledge for all parties (Herremans et al., 2016). Therefore, SE is not only beneficial for 'obtaining' external knowledge, but also for 'commercializing' it (West \& Bogers, 2014); that is, creating and capturing values that are of interest to both the firm and its stakeholders. Consequently, this paper views SE as a means to gaining access to external stakeholders' knowledge in order to conduct SOI, which in turn enables firms to ensure corporate sustainability as their overarching purpose.

By means of an exploratory study, Ghassim and Foss (2018) show that mineral companies rely on a wide range of stakeholders to obtain the technological, scientific, market and social knowledge required to pursue SOI. While customers, suppliers and universities provide firms with the required knowledge of technologies and markets, the necessity to obtain social approval has motivated firms to engage environmental activists and local communities in their innovation processes. This is in accordance with the results of a growing body of literature that draws on the concept of 'social license to operate' to argue that insufficient social knowledge might result in the need to cease or delay operations at a mine (Prno \& Scott 
Slocombe, 2012). For instance, in Northern Europe, where social license is particularly

Closer observation of the attributes of SE directs us to what stakeholder theorists refer to as transactional vs. relational interactions (Hillman \& Keim, 2001; Jones, 1995). In the transactional, or one-way, interaction process, the primary intention of firms is to learn about the needs and expectations of their stakeholders, without their direct involvement in the learning processes (Herremans et al., 2016). This inbound knowledge flow entails use of pecuniary (contract-based) and non-pecuniary (information search) mechanisms to supplement the internal knowledge base (Chesbrough \& Bogers, 2014; Dahlander \& Gann, 2010). For example, in the case of environmental management, Roome and Wijen (2006) discuss the adoption of available sustainable solutions from other companies as a means of providing the basis for change processes and innovation.

Nevertheless, the value of transactional interactions is a matter for debate. As these interactions feature one-way relationships, they may lack sufficient involvement of stakeholders in the creation of new knowledge that is likely to produce unique innovations (Kazadi et al., 2016). However, high quality transactional interactions go beyond ad-hoc and market-based transactions, involving a time dimension that adds to the depth of the relationships and converts them to resources that are not easy to duplicate by competitors (Hillman \& Keim, 2001). In this regard, Holmes and Smart (2009) indicate the importance of spotting 'weak signals' in building an appropriate capability to respond to societal stakeholders' demands. In this case, powerful search mechanisms such as the employment of boundary spanners, increases the frequency of transactions and provides timely access to ideas and opportunities, which in turn results in innovative outcomes. In another study of the Canadian extractive industries, firms that had pursued an active mimicking strategy were also experiencing relatively higher performance in corporate sustainability indicators (Bansal, 2005). The study suggests that firms that continuously adopt existing ideas and solutions from other companies or organizations, such as industry associations, reduce the uncertainty of their social and environmental sustainability practices. A recent literature review by Dangelico (2016) on green product innovations provides strong proof for the positive effect of firms' ability to establish and manage 'intense' knowledge flows from a variety of stakeholders, such as customers, suppliers and special interest groups. Based on the previous discussion, the first hypothesis proposed is:

\section{H1a. Transactional SE, when of high quality, is positively associated with SOI outputs.}

On the other hand, relational, or two-way, interactions entail knowledge exchange processes between a firm and its stakeholders (Onkila, 2011). Known as 'coupled knowledge flow' in the innovation literature, they occur mainly via formal mechanisms such as alliances and socially constructed relationships; for example, personal networks (Faems et al., 2008; West et al., 2014). It is also maintained that relational interactions with external stakeholders are grounded in mutual trust and honesty, hence requiring the focal firm to disclose and share its internal information (e.g. issues, solutions and requirements) in order to establish an effective dialogue with its stakeholders (Gould, 2012; Herremans et al., 2016). Consequently, the probability of creating shared value through SOI depends on the ability of the firm to effectively manage its networks of relationships with multiple stakeholders (Kazadi et al., 2016). This could provide a learning milieu for the firm and its stakeholders in which to reach common understanding of the specific purpose(s) of a sustainable product, process or organizational practice. 
Compared to transactional interactions, their relational counterparts have received more

To the best of our knowledge, only two studies have quantitatively examined the effect of SE on outcomes related to SOI. Ayuso et al. (2011) argue for a positive link between diversity of engagement and the tendency of firms to undertake SOI, but found no support for this hypothesis when controlling for the firms' knowledge management practices. On the contrary, Ketata et al. (2015) found empirical support for their proposition that both the quantity and quality of SE increases the degree of sustainability achieved through a firm's innovations. However, common to both of the above studies is the limitation regarding the dependent variable, i.e. SOI. While in the first study the dependent variable is the tendency of firms, but not the actual innovative outputs, in terms of products, processes or practices, the second study only includes innovative firms in the analysis, hence omitting the baseline (firms with no reported SOI activities). Another caveat to Ketata et al.'s (2015) measure of SOI lies in the fact that it does not represent sustainability-oriented practices, but allows the intrusion of actions such as greenwashing, since it assesses the sustainability-related effects of 'all the innovations' a firm has developed. Coincidental practices do not conform to the definition of SOI (Baumgartner \& Ebner, 2010), which implies that deliberate improvements are an integrated part of a firm's strategy and routines.

\subsection{Linking SOI to FP}

Organization scholars maintain that innovation capability is an important source of superior business performance (Mone et al., 1998). They encourage researchers to establish empirical links between the determinants of this capability, innovation outcomes and FP, in order to clarify the likely value of innovation to firm managers (Crossan \& Apaydin, 2010). In the domain of corporate sustainability, Bocken et al. (2014) developed a conceptual framework to explain how different types of SOI, including technological, social and organizational outcomes, could provide firms with financial benefits, whilst helping them to create social values for their communities. Their proposed business model archetypes range from 'efficiency maximization', aimed at reducing environmental and financial costs, to 'adopting stewardship roles' in society, with the purpose of generating a positive reputation in the community. 
Our point of departure for linking SOI to FP is the natural resource-based view (NRBV) of the firm, a theory that posits that competitive advantage is increasingly dependent on capabilities driven by corporate sustainability (Hart, 1995). By extending the resource-based view (RBV), and closely connected with the dynamic capabilities approach (Teece et al., 1997), NRBV introduces pollution prevention, product stewardship and sustainable development as the three main strategic approaches for continuous reconfiguration of firmlevel resources and capabilities in sustainability contexts (Hart \& Dowell, 2011). As the transition to sustainability implies rapid changes in technologies, market demands, environmental regulations and social expectations (Lozano, 2015), it requires continuous modification in the knowledge base of firms (Teece, 2007). This dynamic capability will then assist them to address the environmental and social issues that are becoming increasingly intertwined with their profitability, thereby gaining advantage against their competitors.

In a narrower approach to SOI, researchers have so far provided convincing empirical evidence to highlight the effect of environmental, and more generally green, innovations on different aspects of firm performance. By examining the link between green product/process innovations and new product success in China, Wong (2013) found that product innovation capability predicts higher product success compared to process innovation capability. In a similar vein, Aguilera-Caracuel and Ortiz-de-Mandojana (2013) show that the intensity of green innovation, measured by the share of registered green patents, is positively related to FP expressed in return on assets (ROA). However, they found no significant performance difference between green innovators and non-green innovators; they believe this emanates from the fact that the financial benefit from such innovations appears in the long term.

While current research has contributed to our understanding of the link between different types of SOI and performance, we have yet to establish whether undertaking various SOI activities at the same time could also provide firms with better FP. The need for such an insight stems from the growing necessity for a holistic approach to SOI; that is, developing innovation capabilities at different levels of process, product and organizational practices (Adams et al., 2016). This can be also perceived in NRBV, where sustainability-related strategies should be interconnected, in the sense that achieving a certain output (for instance, product stewardship) might depend on the existence of others (for instance, pollution prevention) (Hart, 1995). Therefore, considering different types of SOI in isolation might limit our understanding of their interrelation, and the likely positive effect of a broader SOI approach to FP.

In one of the first empirical studies that draws on NRBV, Sharma and Vredenburg (1998) examined whether the capability for continuous innovation, triggered by proactive environmental strategies, predicts different aspects of the competitive advantage of firms. Their findings corroborate this link, hence supporting the assumption that SOI capability is positively related to cost reduction and process optimization, among other benefits. Innovations that target corporate sustainability can be considered as typical examples of valuable, rare and inimitable assets that reflect their competitive potential (Rodriguez et al., 2002). SOI is difficult to imitate because of the participation of several groups of stakeholders in its development (Hillman \& Keim, 2001). Moreover, interactions with stakeholders often involve the exchange of tacit social and environmental knowledge, which is hard to be copied by competitors (Zollo et al., 2013). Accordingly, firms that develop their ability in different types of SOI seem to be in a better position to address social and environmental concerns (e.g. through addressing environmental and social issues), while also improving their financial benefit. Therefore, we hypothesize that:

\section{H2. A firm's SOI outputs positively contribute to its FP.}




\subsection{SOI as a mediator in the association between SE and FP}

Considering hypotheses $\mathrm{H1}$ a and $\mathrm{H} 1 \mathrm{~b}$, which propose a positive association between $\mathrm{SE}$ and SOI, and $\mathrm{H} 2$, which suggests SOI as being positively related to FP, one could also assume that SE might conduce to FP, regardless of the SOI outputs. This alternative explanation is indeed rooted in stakeholder theory, particularly the instrumental approach to stakeholder relationships, which basically proposes that firms practicing SE could outperform their competitors based on various long-term financial indicators (Donaldson \& Preston, 1995; Jones, 1995). However, the empirical studies have shown mixed results (Laplume et al., 2008), implying that the likely effect of SE on FP is contingent upon other variables that should be taken into account.

While the contingency of the SE-FP association has yet to be studied thoroughly, a similar perspective can be found in the literature which examines the association between firms' socio-environmental activities (and/or performance) and their FP. In an effort to address this debate, Dixon-Fowler et al.'s (2013) meta-analysis emphasizes that firms with better environmental performance are more focused on continuous innovation as a strong organizational capability, hence increasing their efficiency by lowering costs. Indeed, environmental management does not directly contribute to financial benefits, but rather cultivates innovation as an organizational capability that generates competitive advantage (Sharma \& Vredenburg, 1998). In the context of SMEs, Martinez-Conesa et al. (2017) found that firms with proactive CSR strategies achieve better financial performance, and that this association could be augmented through improved innovation performance relative to others in their industry.

By applying the contingency perspective to the SE-FP association, we argue that SE may not lead to financial benefit for all firms under all conditions. Unlike previous studies that identify SE as an organizational capability (Ayuso et al., 2006; Watson et al., 2017), our argument posits that even though relationships with stakeholders provide firms with new knowledge resources, they may not result in superior performance if the knowledge is not converted to innovative outputs. Unique innovation capabilities with the potential for competitive advantage could be developed through combinations of external stakeholders' knowledge, as one type of necessary resource, and other resources (e.g. firms' internal knowledge), in order to bring benefits to the firm and its stakeholders (Cohen \& Levinthal, 1990; Teece et al., 1997). For instance, Driessen and Hillebrand (2013) suggest that while addressing the interests of stakeholders is not directly related to indicators of competitive advantage such as FP, it may result in 'valuable, rare and inimitable' organizational capabilities that eventually improve performance. Therefore, it is likely that tapping into external knowledge might not per se be related to firm performance, but instead conduce to the development of a capability that in turn improves FP. This discussion implies a fully mediating role of SOI, leading us to hypothesize that:

\section{H3. SOI fully mediates the association between SE and FP.}

Figure 1 illustrates the theoretical framework described above. It consists of three core elements: SE, SOI outputs and FP. We first test the association between SE, featured in the form of transactional and relational interactions, and firms' SOI outputs. As for the second hypothesis, the effect of SOI on FP is examined. Finally, the indirect effect of SE on FP is investigated in $\mathrm{H} 3$, by introducing $\mathrm{SOI}$ as a mediating variable. 


\section{Methods}

\subsection{Sample and data}

The Norwegian minerals industry serves as the empirical setting for our study. By definition, the industry comprises firms that are involved in the extracting and primary processing of minerals in five main categories: industrial minerals, natural and dimension stone, metallic ores, energy minerals (except oil and natural gas) and construction minerals (Geological Survey of Norway, 2016). Three main criteria guided our choice of empirical setting: the urgency of the corporate sustainability perspective; the high dependency on external knowledge; and the cooperative culture in the Scandinavian context.

First, the minerals industry faces dual concerns in meeting the burgeoning demand for raw materials, in the form of growing environmental and social pressure arising from the negative impacts on natural and social systems (Andersen et al., 2015; GRI, 2011). Since environmental and social challenges are the main causes of mine closures and endanger the economic viability of the industry (Laurence, 2011), mineral companies are required to integrate environmental and social sustainability into their business practices. The doubleedged sword of development in the industry has also led to the formulation of policies and measures to secure a sustainable supply of raw materials within Europe, which is one of the strategic pillars of the EU's Raw Material Initiative (European Commission, 2008). In Norway, the new national strategy for the minerals industry sets clear sustainability objectives, as follows: "The minerals industry must have a proactive approach to social responsibility, must find the best environmental solutions and must be a positive force for growth in the host municipalities" (Ministry of Trade and Industry, 2013, p. 12).

Second, as discussed in section 2.1, SOI entails high dependency on external knowledge. Norway's innovation system is characterized by the great ability of firms to recognize the challenges and opportunities arising from complex situations (such as pursuing corporate sustainability) by searching for solutions from external sources and combining this knowledge with their existing capabilities (Fagerberg et al., 2009). This capability seems to be even more relevant for an SME-dominated industry such as minerals, as organizational flexibility allows firms to respond more efficiently and innovatively to sustainability challenges (BosBrouwers, 2010). Although there is a dearth of specific policies aimed exclusively at innovation in the Norwegian minerals industry, the government intends to augment innovation and collaboration through general policy tools such as tax subsidies and cluster programs.

Third, previous studies in the organization and management literature argue that institutionalized cultural norms such as trust, welcoming critical voices and a long-term approach towards value-creation nurture company-stakeholder cooperation in the Scandinavian business context (Strand \& Freeman, 2015). We therefore consider that our 
empirical setting is an interesting context, as it marries the features of SE and corporate sustainability.

Data regarding SE and innovation activities were gathered by means of an author-designed survey (see Appendix 1) that asked firms to specify their innovation outcomes, relationships with external stakeholders and internal routines for knowledge sharing during the period 2013-2015 (Ghassim, 2018). As argued in section 2.1, existing surveys are unable to capture actual SOI activities. Therefore, we based our questionnaire items on the Community Innovation Survey (CIS) as the most widely used tool for collecting innovation data, but customized the pool of items that were available from the CIS to the dependent and independent variables in this study. Subsequently, Dillman et al.'s (2014) tailored survey approach was carefully followed in testing the questionnaire, configuring the online survey instrument and contacting the target population. Following relevant surveys such as that of CIS, we did not include firms that had fewer than five employees at the end of 2015. Accordingly, 193 companies were identified through the Norwegian Register of Business Enterprises. The questionnaire was directed to company managers, as their perceptions of stakeholders are central in stakeholder relationships (Mitchell et al., 1997). Prior to the survey, we made initial contact with several firms during the annual gathering of the Norwegian Minerals Industry (the industry's trade association) to increase awareness of the study. However, we deliberately avoided using the term 'sustainability', both in our preliminary discussions and in the questionnaire, in order to reduce social desirability bias.

In addition to using established measures as far as possible, we conducted a validity examination that combined cognitive interviews with a small pilot study to establish the construct and face validity of the survey instrument. This examination was helpful in determining whether the respondents had the same understanding of the questions and instructions as the researchers (Dillman et al., 2014). To this end, prior to data collection, a draft of the questionnaire was sent to six chief executive managers (CEOs) from the sample firms and two industry informants, who were interviewed about comprehension of the items and concepts in the questionnaire. This test resulted in some minor adaptations and reformulations of the questionnaire items.

A personalized email invitation was then sent to the CEOs of the 193 companies, including a cover letter and link to the online questionnaire. The email package and questionnaire were administered in Norwegian to ease communication with the firms. We applied a review and adjudication procedure (Harkness et al., 2004) to avoid a mismatch between the meanings of the words and expressions in English and Norwegian. Therefore, the second author first translated the items from English into Norwegian and developed a draft of the questionnaire. A colleague (the second author's supervisor), who was quite familiar with the study topic, then reviewed the draft and suggested some modifications. Finally, another colleague (skilled in survey design and knowledgeable about the topic) studied the draft, suggested modifications, and made the final decisions on which translation options to adopt.

After two rounds of follow-up contacts, 101 companies (a response rate of 52\%) provided complete responses during the period February to April 2017. In some cases (19 out of the 101 received responses), the CEOs referred the survey to another manager in their respective firms who was directly responsible for innovation activities. These included the R\&D manager, regional manager, production manager or health, safety and the environment (HSE) executive. The respondent firms account for $78 \%$ of the total number of employees and $83 \%$ of the total annual sales value of the Norwegian minerals industry.

For firms' FP, we drew on the openly accessible database of accounting data in Norway, called Proff®. The majority of Norwegian firms are legally required to submit their annual accounts to the governmental authorities, which are also used as a reliable open source of 
information, for instance in B-to-B partnerships. In particular, we matched the survey

As described in section 2, SOI is generally categorized into processes, products and organizational practices (Klewitz \& Hansen, 2014). In each of these categories, the questionnaire provided various areas for innovation, and asked managers to specify their innovative outputs in the period 2013-2015. For process innovations, we took the following improvements into account: maximizing resource and energy efficiency; minimizing pollution and creating value from waste; and promoting the use of renewable resources. Product innovations capture the development of mineral products that either serve as an input for new markets, such as renewable energy technologies, or feature improved purity and recyclability. Finally, the organizational dimension of SOI in our study pertains to new practices aimed at obtaining social approval, including three different aspects (Suopajärvi et al., 2016): communication about environmental and social impacts; involvement in the development of a mine; and contribution to the socio-economic welfare of the local community (e.g. creating jobs). For simplicity, we refer to the last category as social innovations. We have thereby opted to follows Adams et al.'s (2016, p. 181) definition of SOI that juxtaposes "social and environmental value" relative to "products, processes or practices" where our approach entails a broad perspective on social innovation that also includes improvements in communication and community engagement (in line with the standard definition of product and process innovation). Similarly, in the context of sustainable business models, Bocken et al. (2014) propose technological, social and organizational outcomes for SOI. SOI is then measured on a four-point scale ( 0 to 3 ), on which 0 indicates no innovations in the three categories described above, and 3 specifies at least one type of innovation in each of the categories.

Regarding SE, we included six different groups of external stakeholders in the questionnaire: customers, suppliers, NGOs/interest organizations, public authorities, competitors/peer companies and universities. Greenwood (2007, p. 322) defines 'high SE' as the situation in which "these activities [transactional and relational interactions] are numerous and/or these activities are of high quality" ${ }^{\prime \prime}$. In other words, high SE is related to both the quantity (variety) and quality (strength) of the relationships with external stakeholders. Whereas the relational mode of SE is inherently intense, transactional interactions denote weak connections between a firm and its stakeholders (Herremans et al., 2016). Accordingly, for transactional interactions (TRA), firms were asked to state how often they sought knowledge from each of the above stakeholder groups, based on a five-point scale from never $(=1)$ to very often $(=5)$. We then calculated the number of stakeholder groups that a firm sought knowledge from as 'often' (=4) and 'very often' (=5), hence considering frequent interactions to be those that are of high quality. Regarding relational interactions (REL), the firms indicated their collaborative activities during the survey period, enabling us to ascertain the number of stakeholder groups that were engaged in these types of interaction. For instance, a firm would score 6 in TRA if it

\footnotetext{
${ }^{\dagger}$ explanation in the brackets added by the authors
} 
was engaged with all the six stakeholder groups often or very often, or 0 if it was engaged with them at medium (=3) or lower levels. On the other hand, a score of 6 in REL shows that the company collaborated with all the stakeholder groups, and 0 if it did so with none of them.

Alongside firms' ROS in 2012, we also controlled for several other variables. R\&D activities and employees' education level may influence the ability of firms to pursue SOI (Ketata et al., 2015). The dummy variable INRD captures whether a firm undertook internal R\&D activities during the period 2013-2015. For education level $(E D N)$, we calculated the proportion of personnel with a university degree. Furthermore, earlier studies suggest that the amount of benefit from SE depends on a firm's internal capacity to share and integrate the acquired knowledge (Ayuso et al., 2011; Wong, 2013). Accordingly, we included the variable 'knowledge assimilation capacity' (ASSIM) as a firm's ability to analyze, interpret and understand knowledge. This was then measured by averaging the scores from a five-point Likert scale (low $=1$, to high $=5$ ) for four questionnaire items adopted from Flatten et al. (2011). Firm size could influence its capacity to pursue sustainability practices, as well as FP (Hörisch et al., 2015). The variable SIZE was loaded to all our models, gauged as the natural logarithm of the number of full-time equivalent employees at the end of 2015. To account for inter-sectorial variety in the minerals industry, the variable SECTOR was introduced as four dummies representing four different types of minerals sector in our final sample. Finally, it is argued that family firms have a higher tendency to strive for corporate sustainability due to the longer-term view of their management teams (Laplume et al., 2008). To this end, the binary variable FAMILY was added to our model.

\section{Analysis and results}

Data analysis was performed by following different SPSS procedures. In the preliminary stage, it was necessary to identify different clusters of firms in terms of their SOI outputs. In this regard, we performed a combined cluster analysis (hierarchical and non-hierarchical procedures), which increased the validity of the final cluster solutions (Ketchen \& Shook, 1996). First, firms' reported process, product and social innovations (if any) were used for a hierarchical cluster analysis (based on Ward's method and the squared Euclidian distance measure), which is particularly appropriate for identification of the number of clusters (Ketchen \& Shook, 1996). By inspecting the dendrogram, a 'seven-cluster' solution became apparent. However, theoretical discussion favors a 'four-cluster' solution, in which firms with a similar number of SOI outputs (0-3) are homogenous. Consequently, in the second step of our cluster analysis, the k-means method was employed to examine the results of the fourand seven-cluster solutions. While the results seemed to be appropriate for both solutions, we followed Ketchen et al.'s (1996) recommendation and re-examined the results for split (halved) sub-samples. The findings show that the four-cluster solution is more consistent; hence, we chose to proceed with our hypothesis tests with four levels of SOI. As shown in Appendix 2, the homogeneity of these four clusters could also be confirmed by the highly significant F-values in the subsequent ANOVA analysis.

\subsection{Descriptive statistics}

Table 1 presents the descriptive statistics and correlation coefficients for the dependent, independent and control variables. Our sample covers a range from micro-companies (5 to 9 employees) to large ones (over 250 employees), with the smallest and largest having 5 and 315 full-time equivalent employees respectively. As for the sector, construction mineral 
companies are highly represented in the sample compared to the other three categories ${ }^{\ddagger}$ (see Appendix 3 for details of the distribution of sample firms in terms of size and mineral sector). However, this over-representation is in accordance with the overall structure of the minerals industry in Norway and would not be an issue for generalizing the findings. On average, ROS in 2016 increased compared to 2012. More in-depth examination of this variable shows that while some companies are struggling with making a profit and even experiencing negative profitability (costs exceeding sales), some were able to assure sustained profit growth over time.

\section{Insert Table 1 about here}

Similarly, the firms in our sample demonstrate different levels of SOI output, which on average appears to be for one SOI type. More specifically, non-innovators account for 44\%; focused innovators (one type of SOI) for 26\%; and strong innovators (two types of SOI) for $21 \%$ of the firms in the sample, with all-round innovators (three types of SOI) constituting 9\%. According to the mean values for TRA and REL, Norwegian mineral companies engaged between one and two external stakeholders in their innovation processes in the survey period. Based on the fairly strong and significant correlation between these variables and SOI, we believe that the low mean values for TRA and REL are due to the extremely low SE of the non-innovators. We further examine this argument when testing the hypotheses.

The correlation coefficients between the independent and control variables, specifically those above 0.5 and which are significant, suggest that multicollinearity might be an issue. We therefore ran a variance inflation factor (VIF) test for all the independent and control variables, which resulted in VIF values ranging from 1.13 to 1.47 . Since these values are well below the rules of thumb of 10 or 4 (O'brien, 2007), we can conclude that multicollinearity is not a serious concern in our analysis.

\subsection{Hypothesis testing}

The first question we examined was the extent to which external SE affects SOI outputs. To this end, we developed hypotheses $\mathrm{H} 1 \mathrm{a}$ and $\mathrm{H} 1 \mathrm{~b}$, respectively addressing the effects of transactional and relational SE. We tested these hypotheses by employing an ordinal logit regression, as the dependent variable is measured on an ordinal scale ${ }^{\S}$. The results are shown in Table 2.

Insert Table 2 about here

A fundamental assumption in ordinal regression is that the effect of independent (including control) variables are the same for each level of the dependent variable. In SPSS, this assumption could be examined by a test of parallel lines (Norušis, 2006), which rejects the similarity of effects (the null hypothesis in this test) when the result is significant. Thus, for each of the models testing $\mathrm{H} 1 \mathrm{a}$ and $\mathrm{H} 1 \mathrm{~b}$, the results for the test of parallel lines is also presented (see Table 2). Overall, our findings indicate non-significant results for this test in all

\footnotetext{
* Although the industry includes a fifth category (energy minerals), there was only one active company in this category in the survey period and we decided not to include it due to the likely problems in making the subject unidentifiable.

${ }^{\S}$ An alternative might be to treat SOI capability as a nominal variable, meaning that different levels of SOI output do not have a natural ordering. Therefore, we also ran the analysis using a multinomial logit model and found similar results to those obtained from ordinal logit regression. The results are available from the authors upon request.
} 
three models (the p-values are greater than 0.1 ); hence, we assume that the predicting variables have identical effects on the various levels of SOI output.

Model 1 is the baseline model, which includes the effect of the control variables ROS2012, INRD, EDN, ASSIM, FAMILY, SIZE and SECTOR. In model 2, we introduce the effect of TRA on the previous model in order to test H1a. As shown in Table 2, the coefficient is positive and highly significant, in agreement with H1a. Model 3, on the other hand, adds the effect of REL to model 1. The regression coefficient is again positive and highly significant, as hypothesized in H1b. Model 4 loads the effects of both independent variables, and corroborates the positive and significant coefficients for the independent variables obtained in the previous models. Model 4, as the final model in the ordinal regression, is highly significant $\left(\lambda^{2}(11)=94.775, \mathrm{p}=.000\right)$, with a McFadden pseudo R-square of .375 , which shows its overall goodness-of-fit. The results described above indicate that both transactional and relational SE are positively associated with SOI. All other things being equal, the odds of achieving higher SOI outputs improve by $99.4 \%$ and $78.9 \%$, with a unit rise in transactional and relational SE respectively. As for the control variables, EDN, ASSIM and SIZE are positive and significant in all the models. The coefficients for inter-sectorial variance show that only the metallic ore firms differ in terms of SOI outputs.

Our second hypothesis suggests that firm's SOI outputs positively contribute to their FP. Linear regression and the multiple OLS method were used to test this hypothesis. As shown in Table 3, we first loaded the effect of the controls into model 5. Subsequently, SOI was added to create model 6 . Concerning the control variables, the regression coefficient for ROS2012 shows that prior FP is an important predictor of subsequent performance. Interestingly, we found that firm size is not significant for FP, whereas non-family firms seems to outperform their counterparts.

Insert Table 3 about here

For the theoretical argument suggested in this study, model 6 provides information about the positive impact of SOI on a firm's FP. More specifically, a single unit increase in SOI (e.g. from one to two types of innovative output) could then increase profitability by $3.186 \%$, a highly significant effect at $\mathrm{p}<0.001$. Comparing the standardized coefficients for ROS 2012 and SOI in model 6, we can observe that the effect of prior FP on subsequent performance is just over twice the effect of SOI on the latter. The goodness-of-fit statistics for model 6 indicate that adding SOI results in a significant improvement compared to model 5 , which only includes controls ( $\mathrm{F}$ change $=13.572, \mathrm{p}<0.001)$.

The final hypothesis of the study (H3) goes beyond the straightforward relationships previously tested, and suggests that SOI fully mediates the SE-FP association. While traditional practice in mediation analysis requires the existence of a significant direct path from predictor to outcome variable, recent advancements in this area argue that such a link is unnecessary (Aguinis et al., 2017). This argument draws on the fact that mediation is established through two paths: (1) from the predictor to the mediator; and (2) from the mediator to the outcome variable. As we have already investigated these two paths in our ordinal and linear regressions ( $\mathrm{H} 1$ and $\mathrm{H} 2)$, the test of $\mathrm{H} 3$ deals particularly with examination of the size and significance of the indirect link between the predictor (SE) and outcome variable (FP).

Accordingly, we followed Zhao et al.'s (2010) instructions for performing mediation analysis in SPSS, which are built upon the Preacher-Hayes bootstrapping script. As we have two predictor variables (TRA and REL), the analysis was made separately for each of them, while 
controlling for the other. Included in both models are our controls, as described above. The results reveal that SOI fully mediates the effect of both TRA and REL on ROS2016, which supports H3. More specifically, for TRA, the mean indirect effect from the bootstrap analysis is positive and significant (effect size $=.741$ ), with a $95 \%$ confidence interval excluding zero (.1991 to 1.6625). Concerning REL, the mean indirect effect is positive and significant (effect size $=.6485)$, with a $95 \%$ confidence interval excluding zero (.1191 to 1.5758$)$. The ratios of indirect to total effect indicate that SOI accounts for $56 \%$ and $50 \%$ of the total effects of TRA and REL on ROS2016 respectively.

\subsection{Robustness checks}

To assess late-response bias, we compared the three groups of respondents, late respondents (including two subgroups of respondents who took part after the reminder email and those who did so after the follow-up phone call) and non-respondents in terms of size, sales value and innovation outcome. The results reveal no significant difference between the groups.

To examine the issue of multicollinearity, we first assessed the correlations between all the dependent (including the control) variables in models 2-6. As shown in Table 1, Spearman's coefficient for four of the correlations between the independent variables (REL and TRA in model 4, and the correlations between SOI with INRD, ASSIM and SIZE in model 6) is above the threshold of 0.5 and is significant, which raises the concern of multicollinearity. This issue was further examined by means of a variance inflation factor (VIF) test and by running linear regression models for all the dependent and control variables. The results show VIF values ranging from 1.04 to 2.31, which are far below the rule of thumb of 10 . Therefore, no potential collinearity problem is indicated.

To reduce common method bias, we adopted both procedural and statistical approaches following the suggestions of Podsakoff et al. (2003). First, two different sources of information (the survey and financial database) were used so that the data for all the predictor and outcome variables were not obtained from the same respondents. We also used different response types, such as Likert scales, yes/no answers, indications of percentages and questions requiring absolute numbers in the questionnaire. Moreover, the respondents were assured full anonymity in order to reduce evaluation apprehension and to obtain reliable answers. As for the statistical remedies, we employed Harman's single-factor test by loading all the variables into an exploratory factor analysis. The unrotated factor solution (the principal component factor analysis) revealed the presence of four distinct factors with eigenvalues greater than 1.0, rather than a single factor. The four factors together accounted for $71 \%$ of the total variance; the first (largest) factor did not account for the majority of the variance (22\%). Thus, no general factor is apparent, suggesting that common method bias is not a substantial threat to the validity of the study.

As discussed in section 4.2 with regard to testing the mediation hypothesis, we opted to use the recent advances in mediation analysis, in which the significance of the direct path from the predictor to outcome variable is no longer a prerequisite. However, the traditional procedure established by Baron and Kenny (1986) can also be partly employed as a robustness check. According to this procedure, SOI outputs mediate the SE-FP relationship when three criteria are met: 1) variations in the levels of SE are significantly associated with variations in SOI outputs; 2) variations in the levels of SOI outputs are significantly associated with variations in FP; and 3) when SOI outputs are included as a control variable, the previously significant associations between SE and FP are no longer significant. Based on the results from the tests of $\mathrm{H} 1$ and $\mathrm{H} 2$, the two first criteria are met, and provide additional support for the mediation hypothesis. 
The lack of a direct association between SE and FP was further investigated by means of oneway ANOVA. To this end, we first grouped firms into three categories according to their FP: those that experienced 1) increasing ROS in the period 2012-16;2) decreasing ROS during the period 2012-16, and 3) almost constant (within a 10\% difference) ROS in the same period. We then performed an ANOVA test to examine if there were any statistically significant differences between the means of these three categories in terms of the two types of SE. Regarding the transactional SE, the test results show a statistically significant difference between the above groups $(\mathrm{F}=4.913, \mathrm{p}=.009)$. A Tukey post hoc test revealed that the difference in TRA was only significant between the 'increasing' and 'decreasing' groups ( $\mathrm{p}=$ .006). This variance is even weaker for REL, for which the results from the ANOVA test show no statistical difference between the three groups $(F=1.934, p=.150)$.

\section{Discussion}

As firms are increasingly pressurized to leverage innovation in the quest for balancing social, environmental and economic sustainability (Klewitz \& Hansen, 2014; Nidumolu et al., 2009), a central question would then concern the antecedents and consequences of accomplishing SOI. In light of the growing literature emphasizing the high importance of SE in tackling sustainability challenges (Hall \& Martin, 2005; Segarra-Oña et al., 2017), this paper sets out to examine the mechanisms through which externally-acquired knowledge could contribute to firms' SOI outputs and financial performance. By drawing on stakeholder theory, we focused on two specific modes of SE, the transactional and relational, and adopted a nuanced approach to quantitatively test the association between SE, SOI outputs and FP. This enabled us to reveal the mediating effect of SOI in the SE-FP association, hence suggesting SOI as a mechanism that conditions the financial benefit from a high level of engagement with external stakeholders.

Concerning the association between SE and SOI, both transactional and relational modes of SE are conducive to a broader range of SOI outputs, covering process, product and social innovations. Given the complexity and uncertainty of adopting such a holistic approach to SOI, SE enables firms to access a diverse range of knowledge resources, which in turn increase their ability to understand socio-technical requirements and to mitigate conflicting interests (Clarke \& Roome, 1999; Watson et al., 2017).

More specifically, regarding transactional SE, firms need to implement ongoing knowledge acquisition activities that compensate for the low direct involvement of stakeholders in these one-way relationships. Assuming external stakeholders to be mere information sources, rather than co-creators of knowledge, may hinder the mutual understanding required for closing the gap between conflicting goals (Kazadi et al., 2016). Others also understate transactional SE from a 'competitive advantage' point of view by arguing that it is easily duplicable by competitors due to the dearth of socially complex resources (e.g. knowledge assets and trust) embedded in them (Hillman \& Keim, 2001). However, our study leads to the conclusion that repeating transactional processes such as actively mimicking the established technical solutions in the market (Bansal, 2005), or employing boundary spanners to spot weak signals from societal stakeholders (Holmes \& Smart, 2009), could provide firms with timely access to external knowledge, and consequently increase the probability of innovation.

Relational SE differs from the transactional in the sense that it requires relatively long-term commitments, together with the desire of the focal firm to share its internal knowledge with external stakeholders. In turn, this trust-based relationship increases the exchange of complex technical and social knowledge (Hillman \& Keim, 2001), especially in the case of highly uncertain innovations which entail a variety of economic, environmental and social risks (Hall \& Martin, 2005). Our results corroborate earlier findings about the importance of engaging a 
diverse set of stakeholders in SOI practices (Goodman et al., 2017; Kazadi et al., 2016; used in previous studies.

As for the association between SOI and FP, we found convincing evidence to support the hypothesis that adopting a holistic SOI approach and broadening the scope of innovations into different areas of process, product and organizational practices, explain superior profitability. While a positive association between narrower approaches to SOI (e.g. technological advances in products and processes) and FP has been identified in previous studies (AguileraCaracuel \& Ortiz-de-Mandojana, 2013; Martinez-Conesa et al., 2017; Sharma \& Vredenburg, 1998), our findings shed more light on SOI as a multi-dimensional capability that enables firms to simultaneously address various sustainability objectives. A firm that focuses on innovations with limited sustainability approaches, for instance environmental process innovations, might not be necessarily more profitable than its counterparts (Aguilera-Caracuel \& Ortiz-de-Mandojana, 2013). Instead, combining advances in technological processes with improvements in product quality and effective communication with societal stakeholders could assist firms to reap the financial benefits of environmental management by differentiating their products in respective markets (Bansal, 2005).

The competitive value of SOI as a unique capability leads us to a description of the results about the full mediation hypothesis. Our results show that a direct association between SE (both transactional and relational) and FP does not exist, as mere access to external knowledge may not denote the 'valuable, rare and inimitable' assets required for superior FP. This contradicts other studies which identify SE as an organizational capability by arguing that relationships with external stakeholders provide firms with access to complementary resources (Ayuso et al., 2006; Watson et al., 2017). While we do not reject the benefit of SE in terms of complementary resources, our data lead us to believe that firms accumulate valuable capabilities when they are able to combine external inputs as one type of resource with other resources, such as their internal knowledge (Cohen \& Levinthal, 1990; Teece et al., 1997). Hence, the SE-FP association is fully mediated by SOI outputs that translate the benefits of SE into financial outcomes. As such, our findings also relate to the literature on open innovation that posits that external sources of knowledge can help to accelerate innovation activities and performance (Chesbrough \& Bogers, 2014; Dahlander \& Gann, 2010), although our study sheds some light on the exact process in which external stakeholders can contribute to performance (Faems et al., 2010; West \& Bogers, 2014). Indeed, the finding that SOI mediates the association between external SE and FP implies that, under certain conditions and in certain contexts, an open innovation approach requires a sustainability orientation to ultimately materialize into a performance benefit.

\section{Conclusions and implications}

This paper contributes to the evidence of SE in pursuing SOI by analyzing how the transactional and relational attributes of relationships with stakeholders affect innovative outputs. The study adds to the understanding of the potential benefits from SE by showing that not only does the variety of stakeholders engaged in innovation processes matter for SOI, but also that engagement practices should be frequent enough to result in strong relationships that motivate effective learning. Therefore, we respond to Hörisch et al.'s (2014) call for more attention to be paid to the intricacies of relationships with external stakeholders, as it is no longer sufficient to answer the question "What types of stakeholder groups should be engaged", but rather "How can dissimilar stakeholders be engaged?" in order to fulfil the various sustainability objectives.

Besides stakeholder theory, this study provides interesting insights into NRBV. While corroborating previous findings that evidence superior performance for firms with higher 
capabilities related to corporate sustainability, this study also extends this insight by suggesting that SE does not per se feature such unique capabilities. Instead, to improve their (financial) performance, firms are required to leverage their relationships with stakeholders in order to transform the external knowledge acquired into innovative outputs, which are likely to act as 'valuable, rare and inimitable' capabilities in light of NRBV.

Based on the above findings, some implications can be formulated for practice. Firm managers should recognize the benefits and limitations of SE with regard to innovative and financial outcomes. Whereas both transactional and relational relationships may enhance firms' capability to make innovations, the manner in which these SE mechanisms conduce to innovative outputs differs. Besides considering the need for engaging a wide set of external stakeholders, specific attention should be devoted to making the engagement practices strong enough (e.g. by increasing the frequency of transactions), in such a way that timely access to knowledge resources and effective learning are secured. However, managers should also be aware of their internal capacity limitations, and the extent to which their human and financial resources should be allocated to external engagement activities. In this regard, transactional SE has advantages over its relational counterpart, as the latter entails mutual commitments and greater pressure to sacrifice one's own interests.

Another lesson from this study is the positive financial effect that broadening the scope of SOI might have. Indeed, focusing on either process, product or organizational innovations may hinder firms from addressing one or another aspect of sustainability, thereby missing their profitability target in the long run. For instance, 'sustainable industrial restructuring' has found its way into policy discourse in Norway and is increasingly changing the strategic orientation of firms in the minerals industry. Therefore, it is expected that firms that lag behind this movement and fail to move beyond the prevalent focus on process innovations might face the risk of sudden changes in customers' product specifications. In addition, building appropriate capabilities for continuously innovating processes, products and organizational practices not only has a direct impact on FP, but is also a mechanism through which the (financial) benefit from engagement activities unfolds.

This study does have some limitations which could motivate future research. Since firms usually do not have enough internal resources to engage intensely with all their external stakeholders, there might exist a trade-off point where performance is optimized. Particular attention should be paid to the marginal returns (in terms of both innovation and financial outputs) from transactional and relational SE, as they are usually used in combination. Accordingly, a potential avenue for SOI research would be to investigate the role of internal factors such as absorptive capacity in moderating the complementary/substitution effect of SE on SOI and FP. Another limitation of the study is inherent in the empirical setting. While examining the associations between SE, SOI and FP in a single industry provides deep insights into how firms in a particular sector respond to sustainability concerns, we encourage future research to test our model in other sector and country contexts. Furthermore, the observed associations enable us to conclude that engaging external stakeholders in SOI processes generates economic, environmental and social improvements, which consequently enhance a firm's FP. However, measuring the actual impact of innovative outputs on the three aspects of sustainability was beyond the scope of this paper, but is certainly an important direction for future research. Finally, SOI is one out of possibly several factors that serve to clarify the nature of the SE-FP association. As this complex association is still underresearched, examining other contingency factors would help to better understand under what conditions the efforts firms invest in engaging stakeholders and addressing broader sustainability concerns would pay off in economic terms.

\section{Declarations of interest: none}


Adams, R., Jeanrenaud, S., Bessant, J., Denyer, D., \& Overy, P. (2016). Sustainabilityoriented Innovation: A Systematic Review. International Journal of Management Reviews, 18(2), 180-205.

Aguilera-Caracuel, J., \& Ortiz-de-Mandojana, N. (2013). Green Innovation and Financial Performance:An Institutional Approach. Organization \& Environment, 26(4), 365385.

Aguinis, H., Edwards, J. R., \& Bradley, K. J. (2017). Improving Our Understanding of Moderation and Mediation in Strategic Management Research. Organizational Research Methods, 20(4), 665-685.

Amini, M., \& Bienstock, C. C. (2014). Corporate sustainability: an integrative definition and framework to evaluate corporate practice and guide academic research. Journal of Cleaner Production, 76(Supplement C), 12-19.

Andersen, A. D., Johnson, B. H., Marín, A., Kaplan, D., Stubrin, L., Lundvall, B.-Å., \& Kaplinsky, R. (2015). Natural resources, innovation and development. Retrieved from http://vbn.aau.dk/files/219166399/Globelics3_2015_online.pdf

Ayuso, S., Ángel Rodríguez, M., García-Castro, R., \& Ángel Ariño, M. (2011). Does stakeholder engagement promote sustainable innovation orientation? Industrial Management \& Data Systems, 111(9), 1399-1417.

Ayuso, S., Rodríguez, M. Á., \& Ricart, J. E. (2006). Using stakeholder dialogue as a source for new ideas: a dynamic capability underlying sustainable innovation. Corporate Governance: The international journal of business in society, 6(4), 475-490.

Bansal, P. (2005). Evolving sustainably: a longitudinal study of corporate sustainable development. Strategic Management Journal, 26(3), 197-218.

Baron, R., \& Kenny, D. (1986). The moderator-mediator variable distinction in social psychological research: conceptual, strategic, and statistical considerations. Journal of Personality and Social Psychology, 51(1986), 1173-1182.

Baumgartner, R. J., \& Ebner, D. (2010). Corporate sustainability strategies: sustainability profiles and maturity levels. Sustainable Development, 18(2), 76-89.

Bocken, N. M. P., Short, S. W., Rana, P., \& Evans, S. (2014). A literature and practice review to develop sustainable business model archetypes. Journal of Cleaner Production, 65, 42-56.

Bogers, M., Chesbrough, H., \& Moedas, C. (2018). Open innovation: Research, practices, and policies. California Management Review, 60(2), 5-16.

Bogers, M., Zobel, A.-K., Afuah, A., Almirall, E., Brunswicker, S., Dahlander, L., Frederiksen, L., Gawer, A., Gruber, M., Haefliger, S., Hagedoorn, J., Hilgers, D., Laursen, K., Magnusson, M. G., Majchrzak, A., McCarthy, I. P., Moeslein, K. M., Nambisan, S., Piller, F. T., Radziwon, A., Rossi-Lamastra, C., Sims, J., \& Ter Wal, A. L. J. (2017). The open innovation research landscape: Established perspectives and emerging themes across different levels of analysis. Industry and Innovation, 24(1), 840.

Bos-Brouwers, H. E. J. (2010). Corporate Sustainability and Innovation in SMEs: Evidence of Themes and Activities in Practice. Business Strategy and the Environment, 19(7), 417435.

Chesbrough, H., \& Bogers, M. (2014). Explicating open innovation: Clarifying an emerging paradigm for understanding innovation. In H. Chesbrough, W. Vanhaverbeke, \& J. West (Eds.), New Frontiers in Open Innovation: 3-28. Oxford: Oxford University Press. 
Clarke, S., \& Roome, N. (1999). Sustainable business: learning - action networks as organizational assets. Business Strategy and the Environment, 8(5), 296-310.

Cohen, W. M., \& Levinthal, D. A. (1990). Absorptive Capacity: A New Perspective on Learning and Innovation. Administrative Science Quarterly, 35(1), 128-152.

Crossan, M. M., \& Apaydin, M. (2010). A Multi-Dimensional Framework of Organizational Innovation: A Systematic Review of the Literature. Journal of Management Studies, 47(6), 1154-1191.

Dahlander, L., \& Gann, D. M. (2010). How open is innovation? Research Policy, 39(6), 699709.

Dangelico, R. M. (2016). Green Product Innovation: Where we are and Where we are Going. Business Strategy and the Environment, 25(8), 560-576.

Dillman, D. A., Jolene D. Smyth, \& Christian, L. M. (2014). Internet, Phone, Mail, and Mixed-Mode Surveys : The Tailored Design Method (4 ed.). Somerset, US: John Wiley \& Sons.

Dixon-Fowler, H. R., Slater, D. J., Johnson, J. L., Ellstrand, A. E., \& Romi, A. M. (2013). Beyond "Does it Pay to be Green?" A Meta-Analysis of Moderators of the CEP-CFP Relationship. Journal of Business Ethics, 112(2), 353-366.

Donaldson, T., \& Preston, L. (1995). The stakeholder theory of the corporation: Concepts, evidence, and implications. Academy of Management Review, 20(1), 65-91.

Driessen, P. H., \& Hillebrand, B. (2013). Integrating Multiple Stakeholder Issues in New Product Development: An Exploration. Journal of Product Innovation Management, 30(2), 364-379.

European Commission. (2008). The raw materials initiative - meeting our critical needs for growth and jobs in Europe. Communication from the Commission to the Council and the European Parliament. COM (2008) 699 final, 4 November 2008.

Elkington, J. (1999). Cannibals with forks: the triple bottom line of 21 st century business. Oxford: Capstone Publishing.

Faems, D., De Visser, M., Andries, P., \& Van Looy, B. (2010). Technology Alliance Portfolios and Financial Performance: Value-Enhancing and Cost-Increasing Effects of Open Innovation. Journal of Product Innovation Management, 27(6), 785-796.

Faems, D., Janssens, M., Madhok, A., \& Van Looy, B. (2008). Toward an Integrative Perspective on Alliance Governance: Connecting Contract Design, Trust Dynamics, and Contract Application. Academy of Management journal, 51(6), 1053-1078.

Fagerberg, J., Mowery, D. C., \& Verspagen, B. (2009). The evolution of Norway's national innovation system. Science and Public Policy, 36(6), 431-444.

Fiske, S. T., Gilbert, D. T., \& Lindzey, G. (2010). Handbook of social psychology (5th ed. ed. Vol. 2). Hooboken, N.J: John Wiley.

Flatten, T. C., Engelen, A., Zahra, S. A., \& Brettel, M. (2011). A measure of absorptive capacity: Scale development and validation. European Management Journal, 29(2), 98-116.

Foxon, T., \& Pearson, P. (2008). Overcoming barriers to innovation and diffusion of cleaner technologies: some features of a sustainable innovation policy regime. Journal of Cleaner Production, 16(1), S148-S161.

Freeman, R. E. (2010). Strategic Management: A Stakeholder Approach. Cambridge: Cambridge University Press.

Geological Survey of Norway. (2016). Mineral Resources in Norway 2015. Retrieved from Trondheim, Norway:

Ghassim, B. (2018). Survey on innovation activities in Norway's minerals industry covering the years 2013-2015 (Publication no. doi/10.18710/ROZ2QY). from DataverseNO

Ghassim, B., \& Foss, L. (2018). Understanding the micro-foundations of internal capabilities for open innovation in the minerals industry: a holistic sustainability perspective. 
Resources Policy. Published online ahead of print: https://doi.org/10.1016/j.resourpol.2018.09.011

Goodman, J., Korsunova, A., \& Halme, M. (2017). Our Collaborative Future: Activities and Roles of Stakeholders in Sustainability-Oriented Innovation. Business Strategy and the Environment, 26(6), 731-753.

Gould, R. W. (2012). Open Innovation and Stakeholder Engagement. Journal of Technology Management \& Innovation, 7(3), 1-11.

Greenwood, M. (2007). Stakeholder Engagement: Beyond the Myth of Corporate Responsibility. Journal of Business Ethics, 74(4), 315-327.

GRI. (2011). Sustainability reporting guidelines \& mining and metals sector supplement.

Hahn, T., Pinkse, J., Preuss, L., \& Figge, F. (2015). Tensions in Corporate Sustainability: Towards an Integrative Framework. Journal of Business Ethics, 127(2), 297-316.

Hall, J. K., \& Martin, M. J. C. (2005). Disruptive technologies, stakeholders and the innovation value-added chain: a framework for evaluating radical technology development. R\&D Management, 35(3), 273-284.

Hall, J. K., \& Vredenburg, H. (2003). The Challenges of Innovating for Sustainable Development. MIT Sloan Management Review, 45(1), 61-68.

Harkness, J., Pennell, B.-E., \& Schoua-Glusberg, A. (2004). Survey Questionnaire Translation and Assessment. In S. Presser, J. M. Rothgeb, M. P. Couper, J. T. Lessler, E. Martin, J. Martin, \& E. Singer (Eds.), Methods for Testing and Evaluating Survey Questionnaires (pp. 453-473): John Wiley \& Sons, Inc.

Hart, S. L. (1995). A natural-resource-based view of the firm. Academy of Management Review, 20, 986-1014.

Hart, S. L., \& Dowell, G. (2011). A natural-resource-based view of the firm : fifteen years after. Journal of Management, 37(5), 1464-1479.

Herremans, I. M., Nazari, J. A., \& Mahmoudian, F. (2016). Stakeholder Relationships, Engagement, and Sustainability Reporting. Journal of Business Ethics, 138(3), 417435.

Hillman, A. J., \& Keim, G. D. (2001). Shareholder value, stakeholder management, and social issues: what's the bottom line? Strategic Management Journal, 22(2), 125-139.

Holmes, S., \& Smart, P. (2009). Exploring open innovation practice in firm-nonprofit engagements: a corporate social responsibility perspective. $R \& D$ Management, 39(4), 394-409.

Hörisch, J., Freeman, R. E., \& Schaltegger, S. (2014). Applying Stakeholder Theory in Sustainability Management. Organization \& Environment, 27(4), 328-346.

Hörisch, J., Johnson, M. P., \& Schaltegger, S. (2015). Implementation of Sustainability Management and Company Size: A Knowledge-Based View. Business Strategy and the Environment, 24(8), 765-779.

Jay, J., \& Gerard, M. (2015). Accelerating the Theory and Practice of Sustainability-Oriented Innovation. MIT Sloan Research Paper No. 5148-15

Jones, T. M. (1995). Instrumental Stakeholder Theory: A Synthesis of Ethics and Economics. The Academy of Management Review, 20(2), 404-437.

Kazadi, K., Lievens, A., \& Mahr, D. (2016). Stakeholder co-creation during the innovation process: Identifying capabilities for knowledge creation among multiple stakeholders. Journal of Business Research, 69(2), 525-540.

Ketata, I., Sofka, W., \& Grimpe, C. (2015). The role of internal capabilities and firms' environment for sustainable innovation: evidence for Germany. $R \& D$ Management, 45(1), 60-75.

Ketchen, D. J., \& Shook, C. L. (1996). The application of cluster analysis in strategic management research: an analysis and critique. Strategic Management Journal, 17(6), 441-458. 
Klewitz, J., \& Hansen, E. G. (2014). Sustainability-oriented innovation of SMEs: a systematic review. Journal of Cleaner Production, 65, 57-75.

Laplume, A. O., Sonpar, K., \& Litz, R. A. (2008). Stakeholder Theory: Reviewing a Theory That Moves Us. Journal of Management, 34(6), 1152-1189.

Laurence, D. (2011). Establishing a sustainable mining operation: an overview. Journal of Cleaner Production, 19(2), 278-284.

Laursen, K., \& Salter, A. (2006). Open for innovation: The role of openness in explaining innovation performance among U.K. manufacturing firms. Strategic Management Journal, 27(2), 131-150.

Lozano, R. (2015). A Holistic Perspective on Corporate Sustainability Drivers. Corporate Social Responsibility and Environmental Management, 22(1), 32-44.

Luyet, V., Schlaepfer, R., Parlange, M. B., \& Buttler, A. (2012). A framework to implement Stakeholder participation in environmental projects. Journal of Environmental Management, 111, 213-219.

Martinez-Conesa, I., Soto-Acosta, P., \& Palacios-Manzano, M. (2017). Corporate social responsibility and its effect on innovation and firm performance: An empirical research in SMEs. Journal of Cleaner Production, 142, 2374-2383.

Ministry of Trade and Industry. (2013). Norway Strategy for the Mineral Industry (K-0725 E). Oslo, Norway.

Mitchell, R. K., Agle, B. R., \& Wood, D. J. (1997). Toward a Theory of Stakeholder Identification and Salience: Defining the Principle of Who and What Really Counts. The Academy of Management Review, 22(4), 853-886.

Mone, M. A., McKinley, W., \& Barker Iii, V. L. (1998). Organizational decline and innovation: A contingency framework. Academy of Management Review, 23(1), 115132.

Nidumolu, R., Prahalad, C. K., \& Rangaswami, M. R. (2009). Why sustainability is now the key driver of innovation. Harvard Business Review, 87(9), 56-64.

Norušis, M. J. (2006). SPSS 15.0 guide to data analysis. Upper Saddle River, N.J: Prentice Hall.

O'brien, R. (2007). A Caution Regarding Rules of Thumb for Variance Inflation Factors. International Journal of Methodology, 41(5), 673-690.

Onkila, T. (2011). Multiple forms of stakeholder interaction in environmental management: business arguments regarding differences in stakeholder relationships. Business Strategy and the Environment, 20(6), 379-393.

Piening, E. P., \& Salge, T. O. (2015). Understanding the Antecedents, Contingencies, and Performance Implications of Process Innovation: A Dynamic Capabilities Perspective. Journal of Product Innovation Management, 32(1), 80-97.

Podsakoff, P., Mackenzie, S. B., Lee, J., \& Podsakoff, N. (2003). Common method biases in behavioral research: A critical review of the literature and recommended remedies. In Journal of Applied Psychology, 88, 879-903.

Prno, J., \& Scott Slocombe, D. (2012). Exploring the origins of 'social license to operate' in the mining sector: Perspectives from governance and sustainability theories. Resources Policy, 37(3), 346-357.

Rodriguez, M. A., Ricart, J. E., \& Sanchez, P. (2002). Sustainable Development and the Sustainability of Competitive Advantage: A Dynamic and Sustainable View of the Firm. Creativity and Innovation Management, 11(3), 135-146.

Roome, N., \& Wijen, F. (2006). Stakeholder Power and Organizational Learning in Corporate Environmental Management. Organization Studies, 27(2), 235-263.

Schaltegger, S., Lüdeke-Freund, F., \& Hansen, E. (2012). Business Cases for Sustainability: The Role of Business Model Innovation for Corporate Sustainability. International Journal of Innovation and Sustainable Development, 6(2), 95-119. 
Segarra-Oña, M., Peiró-Signes, A., Albors-Garrigós, J., \& Miguel-Molina, B. D. (2017). Testing the Social Innovation Construct: An Empirical Approach to Align Socially Oriented Objectives, Stakeholder Engagement, and Environmental Sustainability. Corporate Social Responsibility and Environmental Management, 24(1), 15-27.

Sharma, S. (2005). Through the lens of managerial interpretations: Stakeholder engagement, organizational knowledge and innovation. In S. Sharma \& J. A. Aragón-Correa (Eds.), Corporate Environmental Strategy and Competitive Advantage (pp. 49-70). Cheltenham, UK: Edward Elgar Publishing.

Sharma, S., \& Vredenburg, H. (1998). Proactive corporate environmental strategy and the development of competitively valuable organizational capabilities. Strategic Management Journal, 19(8), 729-753.

Strand, R., \& Freeman, R. E. (2015). Scandinavian Cooperative Advantage: The Theory and Practice of Stakeholder Engagement in Scandinavia. Journal of Business Ethics, 127(1), 65-85.

Suopajärvi, L., Poelzer, G. A., Ejdemo, T., Klyuchnikova, E., Korchak, E., \& Nygaard, V. (2016). Social sustainability in northern mining communities: A study of the European North and Northwest Russia. Resources Policy, 47, 61-68.

Teece, D. J. (2007). Explicating dynamic capabilities: the nature and microfoundations of (sustainable) enterprise performance. Strategic Management Journal, 28(13), 13191350.

Teece, D. J., Pisano, G., \& Shuen, A. (1997). Dynamic capabilities and strategic management. Strategic Management Journal, 18(7), 509-533.

Veldhuizen, M., Blok, V., \& Dentoni, D. (2013). Organisational drivers of capabilities for multi-stakeholder dialogue and knowledge integration. Journal on Chain and Network Science, 13(2), 107-117.

Watson, R., Wilson, H. N., Smart, P., \& Macdonald, E. K. (2017). Harnessing Difference: A Capability-Based Framework for Stakeholder Engagement in Environmental Innovation. Journal of Product Innovation Management, n/a-n/a.

WECD. (1987). Our common future. Oxford: Oxford University Press.

West, J., \& Bogers, M. (2014). Leveraging External Sources of Innovation: A Review of Research on Open Innovation. Journal of Product Innovation Management, 31(4), 814-831.

West, J., Salter, A., Vanhaverbeke, W., \& Chesbrough, H. (2014). Open innovation: The next decade. Research Policy, 43(5), 805-811.

Wilson, M. (2003). Corporate sustainability: What is it and where does it come from? Ivey Business Journal (Online), 1.

Wong, S. K. S. (2013). Environmental Requirements, Knowledge Sharing and Green Innovation: Empirical Evidence from the Electronics Industry in China. Business Strategy and the Environment, 22(5), 321-338.

Zhao, X., Lynch, J., \& Chen, Q. (2010). Reconsidering Baron and Kenny: Myths and Truths about Mediation Analysis. Journal of Consumer Research, 37(2), 197-206.

Zollo, M., Cennamo, C., \& Neumann, K. (2013). Beyond What and Why: Understanding Organizational Evolution Towards Sustainable Enterprise Models. Organization \& Environment, 26(3), 241-259. 
Appendix 1: An overview of the questionnaire used for the survey (translated from Norwegian)

\begin{tabular}{|c|c|}
\hline Question & Measurement scale \\
\hline Number of employees with a master degree or above, at the end of 2015 & Continuous \\
\hline Number of employees with a bachelor degree or vocational certificate at the end of 2015 & Continuous \\
\hline Whether the company is partly/entirely owned by a family & Binary \\
\hline Whether the company is part of a conglomerate & Binary \\
\hline Whether the company is partly/entirely owned by a foreign company & Binary \\
\hline The minerals sector & A dummy consisting of 4 categories \\
\hline $\begin{array}{l}\text { In which geographic market(s) did the company sell product(s) during 2013-2015? (more than one alter } \\
\text { Local market within Norway } \\
\text { Other regions of Norway } \\
\text { Other European countries } \\
\text { All other countries }\end{array}$ & Multiple choice \\
\hline $\begin{array}{l}\text { During 2013-2015, did your enterprise introduce new/significantly improved organizational practice or } \\
\text { extraction/manufacturing that: } \\
\text { Use less energy } \\
\text { Use less raw materials } \\
\text { Control the amount of waste and/or pollution } \\
\text { Are based on renewable energy sources (e.g. hydroelectric) }\end{array}$ & Binary \\
\hline Were any of process innovations introduced during 2013-2015 new to your market? & Binary \\
\hline $\begin{array}{l}\text { During 2013-2015, did your enterprise introduce product innovations in any of the following categories } \\
\text { 1) products that can serve as an input for developing renewable energy technologies } \\
\text { 2) products with higher degree of purity and recyclability }\end{array}$ & Binary \\
\hline Were any of product innovations introduced during 2013-2015 new to your market? & Binary \\
\hline $\begin{array}{l}\text { During 2013-2015, did your enterprise introduce? } \\
\text { New procedures for communicating the potential environmental impacts of the enterprise's activities } \\
\text { New initiatives to advance health, education and employment opportunities for the communities } \\
\text { New routines for involving the local community in the development of your mines }\end{array}$ & Binary \\
\hline
\end{tabular}


Did your company have the following activities regarding the innovations during 2013-2015?

In-house R\&D

Contracting out $R \& D$ services to other enterprises or research organizations

Acquisition of machinery, equipment and software

Competence building such as courses and practical training

Acquisition of existing knowledge from other enterprises or organizations, for example patents

Market introduction of innovations

Design activities

During 2013-2015, how often did you search for knowledge from each of the following sources?

Within the company or conglomerate

Suppliers in the local region

Suppliers in other regions of Norway

Suppliers in other European countries

Suppliers in all the other countries

Customers (potential customers) in the local region

Customers (potential customers) in other regions of Norway

Customers (potential customers) in other European countries

Customers (potential customers) in all the other countries

Competitors/other companies in this industry in the local region

Competitors/other companies in this industry in other regions of Norway

Competitors/other companies in this industry in other European countries

Five-point Likert scale from never

Competitors/other companies in this industry in all the other countries

Universities/research institutes in the local region

Universities/research institutes in other regions of Norway

Universities/research institutes in other European countries

Universities/research institutes in all the other countries

Conference and other meeting places

Professional or academic journals and publications

The industrial associations in Norway

The industrial clusters in Norway

Public organizations such as local and national authorities

Interest organizations and NGOs 
During 2013-2015, did your company cooperate on any of your innovation activities with the enterprises listed below?

Suppliers in the local region

Suppliers in other regions of Norway

Suppliers in other European countries

Suppliers in all the other countries

Customers (potential customers) in the local region

Customers (potential customers) in other regions of Norway

Customers (potential customers) in other European countries

Customers (potential customers) in all the other countries

Competitors/other companies in this industry in the local region

Competitors/other companies in this industry in other regions of Norway

Competitors/other companies in this industry in other European countries

Competitors/other companies in this industry in all the other countries

Universities/research institutes in the local region

Universities/research institutes in other regions of Norway

Universities/research institutes in other European countries

Universities/research institutes in all the other countries

Public organizations in the local region

Public organizations in other regions of Norway

Public organizations in other European countries

Public organizations in all the other countries

NGOs in the local region

NGOs in other regions of Norway

NGOs in other European countries

NGOs in all the other countries

Indicate your level of agreement with the following statements about your relationships with external knowledge sources).

We and our external knowledge sources follow similar rules and laws

We and our external knowledge sources have similar norms and values

Indicate your level of agreement with the following statements about your internal routines for knowledge sharing.

In our company ideas and concepts are communicated cross-departmental.

Our management emphasizes cross-departmental support to solve problems.

In our company there is a quick information flow, e.g., if a unit/employee obtains important information, it will be then communicated promptly to others.

Our management demands periodical cross-departmental meetings to interchange new ideas, problems, and achievements. 


\section{Appendix 2}

Table A1: Results from the hierarchical cluster analysis

\begin{tabular}{|c|c|c|c|c|c|c|c|c|c|}
\hline & & & $\mathrm{i}$ & ii & iii & iv & $\mathrm{v}$ & vi & vii \\
\hline $\begin{array}{l}\text { Preliminary } \\
\text { of SOI outpu }\end{array}$ & ters i & n terms & $\begin{array}{c}\text { No } \\
\text { innovation }\end{array}$ & All & $\begin{array}{l}\text { Only } \\
\text { social }\end{array}$ & $\begin{array}{l}\text { Product } \\
\& \text { social }\end{array}$ & $\begin{array}{c}\text { Only } \\
\text { Process }\end{array}$ & $\begin{array}{c}\text { Process \& } \\
\text { product }\end{array}$ & $\begin{array}{l}\text { Process } \\
\& \text { social }\end{array}$ \\
\hline process & No & Count & 45 & 0 & 9 & 4 & 0 & 0 & 0 \\
\hline innovation & Yes & Count & 0 & 9 & 0 & 0 & 17 & 4 & 13 \\
\hline product & No & Count & 45 & 0 & 9 & 0 & 17 & 0 & 13 \\
\hline innovation & Yes & Count & 0 & 9 & 0 & 4 & 0 & 4 & 0 \\
\hline social & No & Count & 45 & 0 & 0 & 0 & 17 & 4 & 0 \\
\hline innovation & Yes & Count & 0 & 9 & 9 & 4 & 0 & 0 & 13 \\
\hline & & Count & 45 & 9 & 9 & 4 & 17 & 4 & 13 \\
\hline & & $\%$ of all & $44 \%$ & $9 \%$ & $9 \%$ & $4 \%$ & $17 \%$ & $4 \%$ & $13 \%$ \\
\hline
\end{tabular}

Table A2: Results of ANOVA between clusters in terms of different SOI output

\begin{tabular}{|c|c|c|c|c|c|c|}
\hline & & Sum of Squares & df & Mean Square & $\mathrm{F}$ & Sig. \\
\hline \multirow{3}{*}{$\begin{array}{l}\text { whether the company has } \\
\text { introduced a process innovation }\end{array}$} & Between Groups & 57.115 & 1 & 57.115 & 126.982 & .000 \\
\hline & Within Groups & 44.529 & 99 & .450 & & \\
\hline & Total & 101.644 & 100 & & & \\
\hline \multirow{3}{*}{$\begin{array}{l}\text { whether the company has } \\
\text { introduced a product innovation }\end{array}$} & Between Groups & 51.599 & 1 & 51.599 & 102.074 & .000 \\
\hline & Within Groups & 50.045 & 99 & .506 & & \\
\hline & Total & 101.644 & 100 & & & \\
\hline \multirow{3}{*}{$\begin{array}{l}\text { whether the company has } \\
\text { introduced a social innovation }\end{array}$} & Between Groups & 60.113 & 1 & 60.113 & 143.298 & .000 \\
\hline & Within Groups & 41.530 & 99 & .419 & & \\
\hline & Total & 101.644 & 100 & & & \\
\hline
\end{tabular}




\begin{tabular}{cccccccc}
\hline $\begin{array}{c}\text { Company Size } \\
\text { (FTEs) }\end{array}$ & $\begin{array}{c}\text { Micro } \\
\text { (between } \\
\text { 5 and 9) }\end{array}$ & $\begin{array}{c}\text { Small } \\
\text { (between } \\
\text { 10 and 49) }\end{array}$ & $\begin{array}{c}\text { Medium } \\
\text { (between 50 } \\
\text { and 249) }\end{array}$ & $\begin{array}{c}\text { Large } \\
\text { (over } \\
\text { Minerals Sector }\end{array}$ & $\begin{array}{c}\text { Number } \\
\text { of } \\
\text { Firms }\end{array}$ & $\begin{array}{c}\text { Number } \\
\text { of } \\
\text { Employees }\end{array}$ & $\begin{array}{c}\text { Aggregated } \\
\text { Income } \\
\text { (MUSD) }\end{array}$ \\
\hline $\begin{array}{c}\text { Construction minerals } \\
\text { Natural/dimension }\end{array}$ & 21 & 30 & 8 & 0 & 59 & 1680 & 502 \\
stone & 11 & 9 & 3 & 0 & 23 & 604 & 130 \\
$\begin{array}{c}\text { Industrial minerals } \\
\text { Metallic ore }\end{array}$ & 2 & 6 & 6 & 1 & 15 & 1024 & 411 \\
Total & 2 & 0 & 0 & 2 & 4 & 628 & 141 \\
\hline
\end{tabular}

Appendix 3: Distribution of sample firms in terms of size and minerals sector 


\section{Tables}

Table 1: Descriptive statistics and correlation coefficients

\begin{tabular}{|c|c|c|c|c|c|c|c|c|c|c|c|c|c|c|}
\hline & Variable & Mean & SD & Min. & Max. & 1 & 2 & 3 & 4 & 5 & 6 & 7 & 8 & 9 \\
\hline 1 & ROS2016 & 9.8 & 8.848 & -5.45 & 45.63 & & & & & & & & & \\
\hline 2 & SOI & .94 & 1.01 & 0 & 3 & $.36 * *$ & & & & & & & & \\
\hline 3 & TRA & 1.46 & 1.06 & 0 & 4 & .19 & $.56 * *$ & & & & & & & \\
\hline 4 & REL & 1.2 & 1.2 & 0 & 5 & $.39 * *$ & $.62 * *$ & $.59 * *$ & & & & & & \\
\hline 5 & ROS2012 & 8.72 & 9.23 & -20.56 & 48.52 & $.71 * *$ & .11 & .04 & $.24^{*}$ & & & & & \\
\hline 6 & INRD & .12 & .33 & 0 & 1 & .07 & $.52 * *$ & $.44 * *$ & $.4 * *$ & -.11 & & & & \\
\hline 7 & EDN & .17 & .13 & .00 & .63 & .14 & $.41 * *$ & $.25^{*}$ & $.36 * *$ & .12 & .15 & & & \\
\hline 8 & ASSIM & 3.12 & .86 & 1.5 & 4.75 & $.23 *$ & $.54 * *$ & $.34 * *$ & $.38 * *$ & .01 & $.44 * *$ & $.2^{*}$ & & \\
\hline 9 & FAMILY & .63 & .48 & 0 & 1 & -.13 & .07 & .07 & -.06 & -.05 & -.04 & $.24^{*}$ & .03 & \\
\hline 10 & SIZE & 2.94 & 1.13 & 1.61 & 5.75 & .18 & $.51 * *$ & $.34 * *$ & $.39 * *$ & .07 & $.47 * *$ & $.2 *$ & $.29 * *$ & .04 \\
\hline
\end{tabular}

Note: $\mathrm{n}=101$;

$* *$ indicates significance at $\mathrm{p}<0.01$ and $*$ indicates significance at $\mathrm{p}<0.05$. 
Table 2: Regression results for the effect of SE on SOI

\begin{tabular}{|c|c|c|c|c|}
\hline & Model 1 & Model 2 & Model 3 & Model 4 \\
\hline \multicolumn{5}{|l|}{ Threshold } \\
\hline $\mathrm{SOI}=0$ & $3.182^{\dagger}(1.744)$ & $5.197 * *(1.948)$ & $4.069 *(1.811)$ & $5.336 * *(1.983)$ \\
\hline $\mathrm{SOI}=1$ & $5.138 * *(1.835)$ & $7.365 * * *(2.07)$ & $6.276 * *(1.932)$ & $7.626 * * *(2.114)$ \\
\hline $\mathrm{SOI}=2$ & $7.866^{* * *}(1.831)$ & $10.172 * * *(2.09)$ & $9.079 * * *(1.959)$ & $10.462 * * *(2.144)$ \\
\hline ROS2012 & $.011(.024)$ & $.011(.026)$ & $-.006(.027)$ & $-.001(.028)$ \\
\hline INRD & $-2.42(.946)$ & $-1.249(.992)$ & $-1.666(.959)$ & $-.986(1.008)$ \\
\hline EDN & $7.895 * * *(1.973)$ & $7.662 * * *(2.011)$ & $6.194 * *(2.077)$ & $6.581 * *(2.133)$ \\
\hline ASSIM & $.875^{* * *}(.287)$ & $.795^{* *}(.304)$ & $.767 *(.301)$ & $.722 *(.311)$ \\
\hline FAMILY & $-.15(.464)$ & $-.131(.484)$ & $-.446(.49)$ & $-.317(.505)$ \\
\hline SIZE & $.691 * *(.231)$ & $.646 * *(.242)$ & $.645^{* *}(.241)$ & $.624 *(.246)$ \\
\hline \multicolumn{5}{|l|}{ SECTOR categories } \\
\hline Metallic ores & $1.336(1.062)$ & $2.421(1.134)$ & $1.718^{\dagger}(1.116)$ & $2.417 *(1.163)$ \\
\hline Industrial minerals & $-1.041(.686)$ & $-.574(.7)$ & $-.511(.725)$ & $-.297(.735)$ \\
\hline Natural stone & $-.242(.536)$ & $-.487(.563)$ & $.179(.555)$ & $-.119(.581)$ \\
\hline Construction minerals & \multicolumn{4}{|c|}{ Reference category } \\
\hline TRA & & $.923 * *(.266)$ & & $.690 *(.287)$ \\
\hline REL & & & $.804 * * *(.235)$ & $.582 *(.253)$ \\
\hline \multicolumn{5}{|l|}{ Goodness-of-fit } \\
\hline Chi-Square & $76.726 * * *$ & $89.535^{* * *}$ & $88.864 * * *$ & $94.775^{* * *}$ \\
\hline McFadden pseudo $\mathrm{R}^{2}$ & .303 & .354 & .351 & .375 \\
\hline \multicolumn{5}{|l|}{ Test of parallel lines } \\
\hline Chi-Square & 15.304 & 18.045 & 11.156 & 9.097 \\
\hline
\end{tabular}

Note: Standard errors in parenthesis;

$* * *$ indicates significance at $\mathrm{p}<0.001,{ }^{* *}$ at $\mathrm{p}<0.01, *$ at $\mathrm{p}<0.05$ and $\dagger$ at $\mathrm{p}<0.1$ 
Table 3: Regression results for SOI-FP association

\begin{tabular}{lcc}
\hline & Model 5 & Model 6 \\
\hline constant & $.823(3.245)$ & $4.534(3.208)$ \\
ROS2012 & $.696 * * *(.07)$ & $.669 * * *(.066)$ \\
INRD & $-.042(2.552)$ & $-.143(2.509)$ \\
EDN & $.127(5.215)$ & $.019(5.277)$ \\
ASSIM & $.118(.838)$ & $.026(.828)$ \\
FAMILY & $-.157 *(1.367)$ & $-.158 *(1.283)$ \\
SIZE & $.063(0.669)$ & $-.029(.658)$ \\
SECTOR dummies & included & included \\
SOI & & $.363 * * *(.865)$ \\
Adjusted $\mathrm{R}^{2}$ & .49 & .551 \\
$F$-value for $\Delta \mathrm{R}^{2}$ & $14.728 * * *$ & $13.572 * * *$ \\
\hline
\end{tabular}

Note 1: standardized coefficients $(\beta)$ are reported (except for constant). Note 2: Standard errors in parenthesis.

$* * *$ indicates significance at $\mathrm{p}<0.001, * *$ at $\mathrm{p}<0.01$ and $\dagger$ at $\mathrm{p}<0.1$ 